\title{
LOS DESAFÍOS PARA LA PARTICIPACIÓN CIUDADANA DESDE EL CONTEXTO DE LA EMERGENCIA SANITARIA
}

CHALLENGES FOR CITIZEN PARTICIPATION FROM THE CONTEXT OF

THE HEALTH EMERGENCY

Ninfa Elizabeth Hernández Trejo

ninfahernandez@politicas.unam.mx

Facultad de Ciencias Políticas y SOCIALES, Universidad Nacional AutónOMA DE MÉXICO, MÉXICO 
Para citar este artículo:

Hernández Trejo, N. E. (2020). Los desafíos para la participación ciudadana desde el contexto de la emergencia sanitaria. ESPACIO I+D, INNOVACIÓN MÁS DESARROLLO, 9(25). https://doi.org/10.31644/IMASD.25.2020.a05

\section{RESUMEN}

La participación ciudadana se ha visto afectada por la pandemia de COVID-19, no solo por el aplazamiento de algunos mecanismos de democracia directa, como plebiscitos y referéndums, sino también por la ejecución de los ejercicios deliberativos que implica la innovación democrática. En este trabajo se explican estos argumentos a partir del análisis del presupuesto participativo de la Ciudad de México, cuya consulta correspondiente a la convocatoria única de 2020 y 202 I se vio afectada por la emergencia sanitaria.

\section{Palabras clave}

Participación ciudadana, Mecanismos de democracia directa, Innovación democrática, Emergencia sanitaria, COVID-19 


\section{- Abstract-}

Citizen participation has been affected by the COVID-19, not only due to the postponement of some direct democracy mechanisms, such as plebiscites and referendums, but also due to the execution of deliberative exercises that democratic innovation implies. This paper explains these arguments based on the analysis of the participatory budget of Mexico City, whose consultation corresponding to the single call for 2020 and 202I was affected by the health emergency.

\section{Keywords}

Citizen participation, Mechanisms of direct democracy, Democratic innovation, Health emergency, COVID-19 
os procesos políticos llegan a ser la base que da sustento a las democracias, especialmente aquellos en los que la toma de decisiones es compartida con la ciudadanía, para lograr un resultado que armonice las necesidades de los representados con los planes de acción de los gobiernos. Dichos procesos, entonces, van más allá de la renovación de representantes populares (electorales) y cobran relevancia cuando se materializan en procesos participativos, en los cuales hay una constante actividad por parte de los sectores sociales en el ámbito público.

Estos procesos políticos democráticos han encontrado contratiempos para su realización derivados de la emergencia sanitaria. Me refiero a la enfermedad de Coronavirus (COVID-19), que fue proclamada pandemia global el II de marzo de 2020. Se detectó por primera vez en una ciudad de China llamada Wuhan, en diciembre de 2019 , y sus alcances y repercusiones en el mundo han hecho que se modifique la realidad como hasta entonces se conocía. Las esferas social, económica y, por supuesto, la política han tenido que readaptarse a los cambios que ha traído consigo esta contingencia.

Ante las difíciles condiciones a las que se enfrenta el mundo por la pandemia de COVID-19, ha sido necesario y determinante poner por encima de cualquier ejercicio e iniciativa que implique la reunión de personas, los criterios y recomendaciones que ofrecen las autoridades sanitarias para evitar la propagación del virus y mantener la salud de las personas. Lo que ha orillado a reinventar las actividades sociales, incluyendo los procesos políticos democráticos. En este trabajo se busca dar respuesta a la siguiente interrogante: ¿cómo ha impactado la emergencia sanitaria, a raíz del coronavirus, en el desarrollo de la participación ciudadana?

\section{DEFINIENDO LA PARTICIPACIÓN CIUDADANA}

La participación ciudadana implica establecer un diálogo entre la ciudadanía y los gobernantes, de manera que ésta tenga información sobre determinadas cuestiones públicas que le afectan, pueda comunicarla a sus representantes políticos (Colombo, 2006) y que la toma de decisiones sea compartida. En otras palabras, es reducir la brecha existente entre representantes y representados, a partir del involucramiento de los segundos en la cosa pública. Por lo tanto, debe entenderse que sin participación ciudadana no es posible entender la construcción de una democracia.

Siguiendo a N. Cunill (I99I), es posible identificar cuatro tipos de participación con base en el grado de interacción y penetración de las y los actores sociales en el Estado: 
- Participación política, cuyo propósito es influir en el proceso político y en el resultado del mismo. Particularmente, son aquellas acciones y conductas que "apuntan a influir de manera más o menos directa y más o menos legal sobre las decisiones, así como la misma selección de los detentadores del poder en el sistema político o en cada organización política ..." (Pasquino, 20 I I: 70). El ejemplo más claro es la votación para la renovación de representantes populares, pero también está contenida aquí la participación en algún movimiento social.

- Participación social, que se desarrolla entre la ciudadanía sin que haya una interacción con el aparato estatal. Por ejemplo, las y los activistas que buscan atender problemáticas específicas, como de derechos humanos o medio ambiente.

- Participación comunitaria, cuyo objetivo es promover actividades de autogestión de la ciudadanía en su colectividad. Ejemplo de ello serían las asociaciones de colonos que se reúnen por diferentes periodos para atender problemas de sus comunidades, como pavimentación, luz eléctrica, agua potable.

- Participación ciudadana, que implica la intervención de la ciudadanía en los asuntos colectivos "con el fin de mantener, reformar o transformar el orden social y político” (Velásquez y González, 2004: 2).

A diferencia de los otros tipos, la participación ciudadana solamente permite la incursión de la ciudadanía en el proceso de toma de decisiones. Más importante aún es señalar que el resultado de esa toma de decisiones impacta a la sociedad en su conjunto y no solo a las y los ciudadanos que están participando.

Los medios para expresar esa participación ciudadana remiten, hoy en día, a pensar en verdaderos mecanismos de control hacia los entes gubernamentales, de rendición de cuentas y de acceso a la información ciudadana para vigilar la gestión gubernamental $y$, en general, los procesos políticos. Es por ello que se puede distinguir entre dos tipos de mecanismos o instrumentos para la manifestación de la participación ciudadana: los Mecanismos de Democracia Directa (MDD) y la innovación democrática.

Por un lado, los MDD son los primeros procedimientos que fueron incorporados en la historia de la humanidad con el propósito de que la ciudadanía tuviera una mayor incidencia y participación en la toma de decisiones (en la mayoría de los casos) “directamente en las urnas, más allá de la elección de sus representantes” (Welp y Massüger, 2013). Todos estos son formas institucionales ya que están reguladas por los ordenamientos legales. En suma, es posible identificar cinco Mecanismos de Democracia Directa: el referéndum, el plebiscito, la consulta popular, la revocación del mandato 
y la iniciativa ciudadana, en donde el referéndum se utiliza para establecer o anular una o varias disposiciones de carácter legislativo. El plebiscito es un mecanismo que permite aceptar o rechazar actos de gobierno. La consulta popular implica someter a consideración de la ciudadanía cualquier tema que tenga impacto trascendental, por medio de preguntas directas. La revocación del mandato permite a la ciudadanía decidir si una o un representante popular termina su mandato de forma anticipada. $Y$ la iniciativa ciudadana supone la participación ciudadana directa en el proceso legislativo proponiendo leyes y reformas.

Por otro lado, están los mecanismos de innovación democrática. Este es un término moderno que alude a nuevas formas de acercar a la ciudadanía al proceso de toma de decisiones y presenta características bien definidas que la hacen diferente a los MDD. El origen del término está asociado con una especie de giro deliberativo de la democracia, donde la información, asociación, discusión e involucramiento de la ciudadanía se hacen presentes para la toma de decisiones.

A diferencia de los MDD, los de innovación democrática no están necesariamente institucionalizados o regulados por alguna legislación, y son más elaborados, pues exigen una mayor implicación ciudadana para que puedan desarrollarse. Asimismo, otra característica es que su implementación llega a ser más replicada y con éxito en el ámbito local que en el federal, debido a la facilidad que tiene la ciudadanía de tomar decisiones sobre su entorno inmediato.

Algunos ejemplos de innovación democrática son el presupuesto participativo (del cual sostengo que es el mecanismo más ejemplar y reconocido de este tipo); las conferencias nacionales de políticas públicas (de Brasil); los consejos vecinales (de Montevideo); las administraciones zonales (de Quito); los encuentros ciudadanos (para el caso de Bogotá); o los foros legislativos existentes en países como Brasil, Chile, Colombia, Guatemala y Perú. En realidad hay decenas de ejemplos más y son tan variados que nos permiten observar la rapidez de su expansión, lo cual se debe también a los propios déficits de la democracia representantiva.

La introducción tanto de los MDD como de innovación democrática puede ser producto de la voluntad e iniciativas de los poderes públicos, pero también de la sociedad, exigiendo más espacios de discusión e incidencia en la toma de decisiones. En ambos tipos de expresiones de participación ciudadana se desarrollan experiencias a nivel internacional, mismas que se han visto afectadas por la pandemia. 


\section{PROCESOS PARTICIPATIVOS FRENTE A LA EMERGENCIA SANITARIA}

Mucho se ha hablado sobre las implicaciones que la emergencia santinaria ha dejado en los procesos electorales, pero poco se ha profundizado en el impacto que tiene en los procesos de participación ciudadana. Si bien la renovación de nuestros representantes populares genera un efecto político mayor que la celebración de un referéndum (por ejemplo), porque en muchas latitudes las elecciones siguen siendo el principal instrumento para incidir en el espacio público, ambos ejercicios políticos abonan al desarrollo de las democracias. Por lo tanto, se vuelve conveniente hacer una distinción entre ambos tipos para generar recomendaciones más atinadas, porque cada uno presenta retos específicos frente a la emergencia sanitaria.

Ahora bien, es una realidad que los procesos participativos se realizan con menos frecuencia que los electorales a nivel global y esto se debe a la heterogeneidad mundial en torno a la implementación tanto de MDD como de innovación democrática. Es decir, mientras que 66 países (y/o regiones) han suspendido o aplazado procesos electorales, solo siete han hecho lo mismo para referéndums y plebiscitos por la pandemia (IDEA Interncional 2020):

I. El referéndum sobre los cambios en el tribunal constitucional de Armenia.

2. El referéndum sobre el aborto en Gibraltar, territorio británico de ultramar.

3. El plebiscito constitucional en Rusia, que estaba programado para el 22 de abril y que se realizó el I de julio de 2020.

4. El referéndum de circunscripción única, de Islas Malvinas,Territorio de Ultramar del Reino Unido, a celebrarse el 26 de septiembre de 2020.

5. El referéndum de Italia para reducir el número de escaños en el parlamento, a celebrarse en septiembre de 2020.

6. El referéndum de Nueva Caledonia, colectividad especial de Francia, a celebrarse el 8 de octubre de 2020.

7. El plebiscito constitucional de Chile, a celebrarse el 25 de octubre de 2020, a reserva de fijar una nueva fecha posterior por el número de personas contagiadas.

De estos siete, el de Rusia ya se celebró y lo hizo en tiempos de pandemia, al igual que un referéndum constitucional que se efectuó en Guinea. Este último se realizó el 22 de marzo de 2020 (a la par de las elecciones legislativas) y el resultado fue que el $92 \%$ de los votos fueron a favor del sí. Sin embargo, su desarrollo se vio opacado por actos de violencia que se presentaron durante la jornada electiva (Rincón, 2020). En tanto que el refrendo ruso 
sometió a consideración ciudadana las enmiendas constitucionles que, entre otras cosas, permiten al presidente de la nación postularse para dos mandatos más y fue aprobado con aproximadamente el $78 \%$ de votos, frente al $22 \%$ en contra (Hodge e llyushina, 2020).

Asimismo, a inicios de la pandemia en la región latinoamericana, los días 21 y 22 de marzo de 2020 se celebró una consulta ciudadana en Mexicali, Baja California, México, para que la ciudadanía decidiera si se terminaba de construir o no la planta de cerveza Constellation Brands en la región. Según datos proporcionados por la Secretaría de Gobernación participaron más de 36 mil personas ciudadanas, de las cuales el $76 \%$ votó en contra de la cervecera (Martínez, 2020). Este ejercicio tuvo críticas, no solo por los resultados y logística de la consulta, sino también por la falta de medidas sanitarias necesarias ante la pandemia.

En términos generales, tanto las consultas como los plebiscitos, los referéndums y la revocación del mandato presentan una dinámica de ejecución similar al de las elecciones para la renovación de representantes; esa es la lógica que los distingue como mecanismos de democracia directa. Es decir, la ciudadanía -de manera masiva- acude a las urnas a emitir su voto a favor o en contra de alguna propuesta y en ello se concentra la toma de decisiones.

Instituciones como la Organización de los Estados Americanos (OEA) o el Instituto Internacional para la Democracia y Asistencia Electoral (IDEA Internacional) han emitido una serie de recomendaciones para la celebración de elecciones ante esta coyuntura, que incluiría a los referéndums, plebiscitos y consultas ciudadanas. La OEA particularmente lanzó su Guía para organizar elecciones en tiempos de pandemia, en julio de 2020, que propone medidas específicas a partir de seis componentes en atención al ciclo electoral. Por mencionar algunas: asignar los recursos suficientes para implementar las medidas sanitarias en el plan de elecciones; considerar en su organización la inclusión de kit sanitarios para los miembros de mesa, el diseño y producción de mobiliario que permita el distanciamiento físico y facilite la desinfección, el uso de la tinta indeleble y el material educativo en materia sanitaria que se debe desarrollar; el kit debe contener por lo menos máscaras, alcohol en gel, desinfectantes a base de alcohol o cloro para limpieza, jabón, toallas de papel, bolsa para residuos, entre otros; elaborar un protocolo sanitario para el personal que participa de las actividades de logística; habilitar horarios preferenciales de atención a adultos mayores, mujeres embarazadas y personas con afecciones subyacentes, para disminuir su riesgo de contagio; trasladar gestiones presenciales, como la recolección de firmas para promover referéndums, a plataformas digitales o modalidades que reduzcan la presencia física en oficinas del órgano electoral; entre otras (OEA, 2020: 27-2I2). 
Ahora bien, ¿qué sucede con los mecanismos de innovación democrática? La participación ciudadana implica mucho más que salir a votar: estos tienen la característica del componente deliberativo, por lo que la reunión entre ciudadanía y el intercambio de ideas sobre ciertos temas de interés público es fundamental. Pero en este contexto de emergencia sanitaria la concentración de personas está prohibida por el riesgo de cotagio. Es por ello que se sostiene la idea de que resultan mucho más afectados en el marco de la pandemia, pues no se puede desarrollar la deliberación si no sucede el ejercicio asambleario que la desemboca.

Me concentraré en el presupuesto participativo, que es un mecanismo que permite a la ciudadanía decidir sobre una parte del gasto público (Goldfrank, 2006; de Souza, 2003) con el objetivo de optimizar su condición de vida (Ayala y Hernández, 20I4; Marquina, 20I3; Francés, et al, 2007). El de Porto Alegre, en Brasil, es el caso pionero y su éxito fue reconocido ampliamente por representar una de las mejores prácticas de gestión urbana en el mundo (de Sousa, 2003). Su funcionamiento es que se celebran asambleas por temas y se eligen a los delegados y consejos que se encargan de guiar las discusiones (Avritzer, 20 I3; Dagnino, et al., 2007), después la ciudadanía vota para decidir qué proyectos de todos los propuestos deben ser implementados.

Lo común en estos mecanismos es que se celebre por lo menos una asamblea durante su proceso. En el caso del presupuesto participativo de la Ciudad de México, derivado del nuevo diseño institucional que trajo consigo la aprobación de la Ley de Participación Ciudadana de la Ciudad de México (que vino a reemplazar a la del otrora Distrito Federal), las ocho fases o etapas que componen el proceso participativo son: I) emisión de la convocatoria; 2) asambleas de diagnóstico y deliberación; 3) registro de proyectos; 4) validación técnica de los proyectos; 5) día de la consulta; 6) asambleas de información y selección; 7) ejecución de proyectos; y 8) asambleas de evaluación y rendición de cuentas (Art. I20, LPCCM), de éstas, tres corresponden a asambleas: las de diagnóstico y deliberación, las de información y selección y las de evaluación y rendición de cuentas.

La más reciente experiencia del presupuesto participativo ocurrió el I 5 de marzo de 2020, cuatro días después de que el coronavirus fuera decretado pandemia global. Esto ha tenido efectos negativos en la participación ciudadana derivada del mecanismo, como se verá a continuación. 


\section{PRESUPUESTO PARTICIPATIVO DE LA CIUDAD DE MÉXICO Y EL EFECTO DE LA COVID-19}

La Convocatoria Única para la elección de las Comisiones de Participación Comunitaria (Copaco) 2020 y la consulta de Presupuesto Participativo 2020 y 202 I se emitió el 16 de noviembre de 2019 . En el desahogo de las etapas del proceso, enmarcadas en la Ley de Participación, sin problema se realizaron las asambleas de diagnóstico y deliberación (del 17 de noviembre al 8 de diciembre de 2019), mediante las cuales la ciudadanía dialogó sobre las principales necesidades y problemáticas de sus Unidades Territoriales (UT). ' Ello debido a que aún no se había importado la pandemia a México.

Sin embargo, después de la jornada participativa ya no se pudo seguir adelante con el resto de las etapas establecidas en la convocatoria, porque casi de manera inmediata se decretaría Fase II de la pandemia en México, el 23 de marzo de 2020. Con ello se suspenderían muchas actividades, incluidas las del Instituto Electoral de la Ciudad de México (IECM), encargado de organizar los procesos electorales y participativos de la entidad capital mexicana.

De hecho, para cuando ocurrió la jornada participativa ya se habían detectado los primeros casos de coronavirus en el país (desde finales de febrero). Además, para ese 15 de marzo, ya habían 53 casos confirmados (siete más que el día anterior), y 18 de ellos se ubicaban en la Ciudad de México (Gobierno de México, 2020). Es cierto que apenas estaba iniciando el brote pandémico, pero aquí se sostiene que este factor influyó en los resultados de la participación ciudadana del presupuesto participativo.

El presupuesto participativo de la Ciudad de México se implementa desde el año 201 I de manera anual (con excepción del 2019). En éste, la ciudadanía tiene la oportunidad de participar en las asambleas programadas, registrando proyectos y en la consulta, para que decida, de entre los propuestos, para que uno se desarrolle en su UT. Esta consulta ha coincidido en tres ocasiones ya con la elección de órganos de representación ciudadana a nivel colonia, que antes eran los comités ciudadanos y consejos de los pueblos y hoy son las Comisiones de Participación Comunitaria. ${ }^{2}$ Es decir, la elección y la consulta se han realizado de manera concurrente en 2013 , 2016 y 2020. Cuando esto ocurre, la participación ciudadana ha sido más elevada, como puede observarse en la Gráfica I.

1 Por Unidad Territorial entiéndase "las Colonias, Unidades Habitacionales, Pueblos y Barrios Originarios que establezca el Instituto Electoral” (Art. 2, LPCCM) de la Ciudad de México.

2 Es un órgano de representción ciudadana, "conformado por nueve integrantes, cinco de distinto género a los otros cuatro, electos en jornada electiva, por votación universal, libre, directa y secreta. Tendrán un carácter honorífico, no remunerado y durarán en su encargo tres años" (Art. 83, LPCCM). 


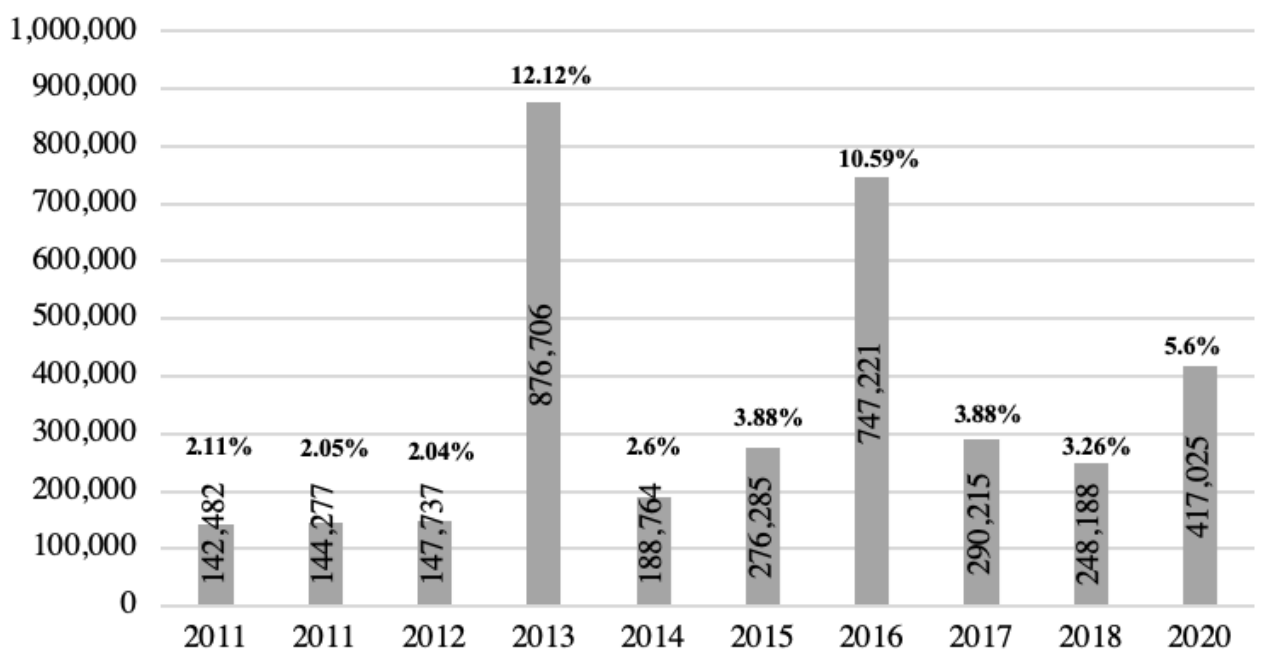

Gráfica 1. Participación ciudadana en las consultas de presupuesto participativo de la Ciudad de México. Fuente: Elaboración propia con datos del Instituto Electoral de la Ciudad de México (IECM)

Estas alzas se deben a que la ciudadanía participa más en la elección de dichas figuras de representación, porque en torno a éstas se han gestado prácticas clientelares con los partidos políticos, sobre todo los más grandes en la ciudad en ese momento: el Partido de la Revolución Democrática (PRD), el Partido Revolucionario Institucional (PRI) y el Partido Acción Nacional (PAN), los cuales los han utilizado para beneficiarse electoralmente (sobre todo los dos primeros), (Zermeño, 2004). Estas dinámicas fueron evidenciadas, por poner un ejemplo, cuando un diputado local perredista repartió mochilas y cuadernos en Cuajimalpa de Morelos, un día antes de la elección, para favorecer a las planillas de comités ciudadanos afines a su partido (Rodea, 2016). ${ }^{3}$

Pues bien, la consulta de presupuesto participativo de 2020 coincidió con la elección de figuras de representación, pero en esta ocasión no se logró el porcentaje de participación esperado. La Gráfica 2 muestra una proyección de la votación esperada para este último ejercicio que, según el pronóstico estadístico sería de 456 mil 814 votantes (6.13\%), sin embargo, la participación registrada fue del $5.6 \%$, equivalente a 417 mil 25 votos, casi 40 mil menos de lo esperado.

3 Para profundizar en este tema se puede consultar la tesis doctoral denominada "Innovación democrática y las condicionantes de la participación ciudadana: análisis del presupuesto participativo en la Ciudad de México", presentada por N. E. Hernández Trejo el 12 de febrero de 2020 (Disponible en https://unam. academia.edu/NinfaElizabethHernándezTrejo/Tesis) 


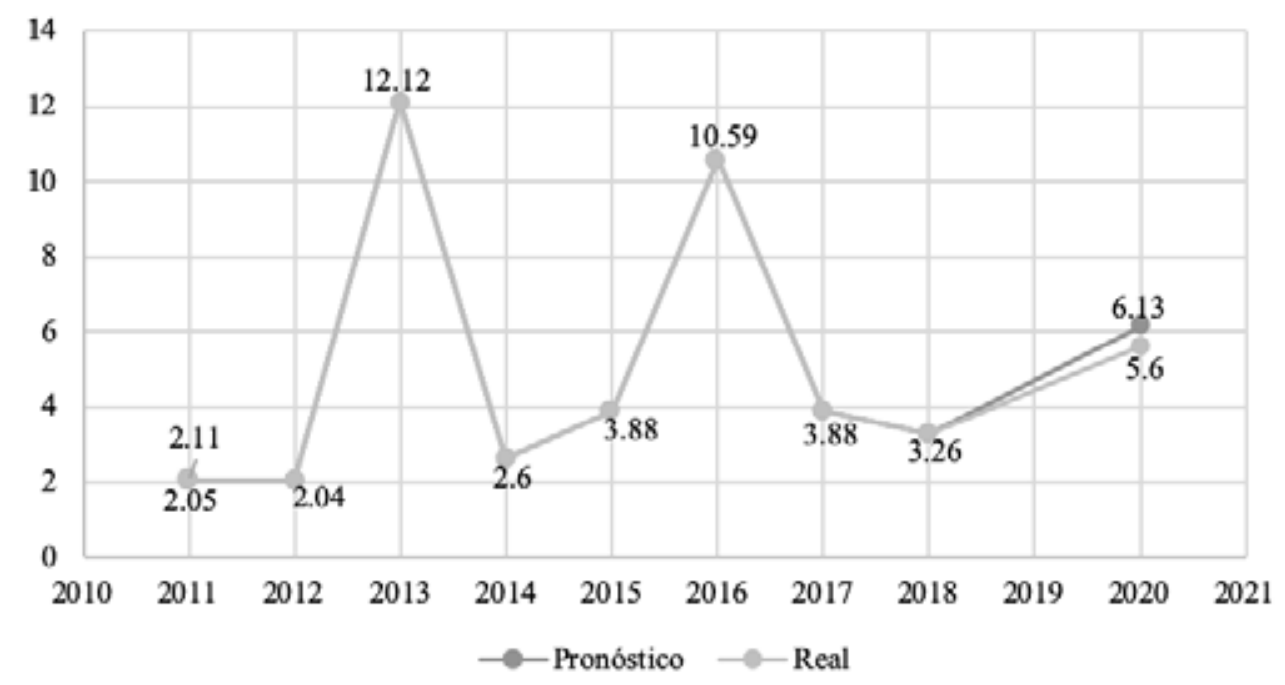

Gráfica 2. Procentaje de participación (2011-2020) y pronóstico para la consulta de 2020, del presupuesto participativo de la Ciudad de México. Fuente: Elaboración propia con datos del Instituto Electoral de la Ciudad de México (IECM)

Este resultado bien puede ser un efecto directo de la pandemia, que desincentivó la participación ciudadana, por el riesgo de contagio. Otro factor que pudo haber incidido es que ese 15 de marzo fue uno de los días de "puente" (pues el lunes 16 de marzo fue día inhábil) y quizá mucha gente no se encontraba en su domicilio. Quizá pudo haber influido el hecho de que, a diferencia de los comités ciudadanos y consejos de los pueblos, la ciudadanía no tuvo conocimiento de la renovación de estas nuevas figuras representativas: las Copaco, y por lo tanto no salieron a votar. Y un último supuesto es que, quizá, a diferencia de experiencias pasadas, en esta ocasión no se desarrollaron prácticas clientelares, ni de "compra de votos", para elegir a determinadas candidaturas de Copaco.También es probable que los cuatro supuestos, en conjunto, hayan influido en el resultado.

Aun así, se sigue sosteniendo que el coronavirus es un factor que generó afectaciones a la participación ciudadana. Esto es así no solo por los resultados de la consulta, sino también por la imposibilidad de concluir el proceso participativo mismo.

Es decir, luego de la jornada y de darse a conocer los resultados, ya no se pudieron efectuar las asambleas de atención de casos especiales, ni las de información y selección, ni mucho menos ejecutarse los proyectos y celebrarse las asambleas de evaluación y rendición de cuentas. Por lo que las tres últimas fases del presupuesto participativo quedaron inconclusas. En lo que respecta a las asambleas para la atención de casos especiales, no están estipuladas en la Ley de participación, pero fueron propuestas en la convocatoria para definir la situación de aquellas UT en las que: I) 
no se celebrara la jornada participativa; 2) no se contara con un proyecto para ejecutar; 3 ) los proyectos sometidos a consulta no hubiera recibido opinión alguna;y) 4) existiera empate entre el primero y el segundo lugar de proyectos (Base Décima de la Convocatoria Única). Éstas debían realizarse del 22 al 29 de marzo de 2020.

Posteriormente se efectuarían las asambleas de información y selección, cuya finalidad es dar a conocer los proyectos ganadores y conformar a los Comités de Ejecución y de Vigilancia en cada UT. Los primeros son los encargados de ejecutar los proyectos de presupuesto participativo y los segundos de verificar que los recursos se apliquen de manera correcta. Ambos se integran por las dos personas ciudadanas que lo deseen y que resulten insaculadas en el sorteo realizado en el marco de este tipo de asambleas. Estaban consideradas a celebrarse durante el mes de abril de 2020.

Acto seguido, se llevaría a cabo la ejecución de los proyectos, desde ese momento y hasta el último día del año en curso, para dar cabida a la fase final, que es la de las asambleas de evaluación y rendición de cuentas. A través de éstas se darán a conocer informes sobre el avance de los proyectos y el ejercicio de los recursos, y se podrán realizar tantas como sea posible; dichos ejercicios estaban programados en la convocatoria para el segundo semestre del año.

Hago notar en este punto que la deliberación se convirtió en ese componente de la participación ciudadana, desde los mecanismos de innovación democrática, más afectado por la pandemia, pues se percibió como imposible de materializarse en estos tiempos donde el necesario distanciamiento social afecta la tarea de reunirnos y dialogar frente a frente.

Precisamente fue esta percepción la que orilló al Congreso de la Ciudad de México a posponer para 202I la ejecución de los proyectos del presupuesto participativo de $2020 .{ }^{4}$ El argumento, legítimo, de esta iniciativa, fue que ya no daba mucho tiempo de ejercer el recurso este año y que en su posible intento se corría el riesgo de contagio por coronavirus. Sin embargo, también se alegó que las asambleas pendientes para la ejecución no podían concretarse debido a las restricciones derivadas de la emergencia sanitaria, lo cual es parcialmente falso.

Cuando el IECM (al igual que muchas otras instancias en México y el resto del mundo) comenzó a innovar en las formas de continuar con sus

4 El 24 de julio aprobó la adición de un transitorio a la Ley de Participación, que establece que: "En virtud de la pandemia originada por el Covid-19, así como la imposibilidad real para continuar de manera adecuada con el proceso de presupuesto participativo 2020, la ejecución de los recursos destinados a los proyectos ganadores seleccionados para dicha anualidad, será realizada en el año 2021" (Art. Vigésimo Transitorio, LPPCCM). 
actividades desde casa, haciendo uso de las tecnologías, empezó a plantear también la posibilidad de que las etapas pendientes de la Convocatoria Única se realizaran vía remota. Por eso es que las Tecnologías de la Información y Comunicación $(\mathrm{TIC})^{5}$ se han convertido en herramientas necesarias en esta coyuntura de pandemia, sobre todo Internet, que solventa la consigna de distanciamiento social, fundamental para evitar la propagación del virus.

\section{USO POLÍTICO DE LA TECNOLOGÍA COMO ALTERNATIVA}

La Guía para organizar elecciones en tiempos de pandemia contempla también un apartado sobre el uso de la tecnología. En ésta se señala que "Las condiciones sanitarias relacionadas con la pandemia de COVID- 19 han provocado que, con mayor celeridad, se explore la utilización de tecnologías de la información y herramientas en línea para brindar soluciones que prevengan o disminuyan el contacto físico de las personas" (2020: 87) en estos procesos políticos. Pero también queda advertido en el documento que en su empleo debe garantizarse la existencia de infraestructura informática, recursos financieros, personal idóneo, capacitación, y otros elementos más con los que no siempre se cuenta en todos los casos. ${ }^{6}$

La urgencia por desahogar todas las actividades pendientes de la convocatoria ocasionaron que el instituto electoral capitalino pensara en la posibilidad de efectuar las asambleas de manera remota, desde antes de que el Congreso de la Ciudad tomara la decisión de aplazar la ejecución de los proyectos para 202I. En esta premura, no realizó un diagnóstico sobre la capacidad de implementar la tecnología, sino que basó su iniciativa más en la priorización a partir de la mitigación de los contagios, para seguir adelante con sus tareas.

La oferta consiste en que estas asambleas se celebren en un modelo mixto: virtual y presencial (esta última en la medida que la propia pandemia lo permita). Para su desarrollo virtual se tiene contemplado que la Unidad

5 Las TIC son los medios que nos brindan un flujo ininterrumpido de información que es empleada en todos los aspectos de la vida cotidiana de las personas. Engloban a la prensa, la radio, la televisión, el cine y la red mundial. Hay que destacar un explosivo desarrollo de la Internet, que permite comunicación diferida o en tiempo real.

6 Algunas de las acciones propuestas en la guía son: realizar un diagnóstico sobre la capacidad para implementar la tecnología; priorizar a partir de la mitigación de los contagios; incorporar en las decisiones a las áreas informáticas del órgano electoral; ampliación de contratación de personal técnico calificado que fortalezca el área informática del órgano electoral; procurar una implementación progresiva y gradual; que haya un plan de seguridad informática; que se generen pruebas piloto; considerar que la introducción de herramientas tecnológicas puede requerir una capacitación diferenciada (OEA, 2020: 85- 104). Muchas de estas recomendaciones implican mayor tiempo y recursos para desarrollarse y existen otras que, al parecer, van a representar un problema continuo: el acceso a la tecnología, por las desigualdades latentes en muchas latitudes del mundo. 
Técnica de Servicios Informáticos (UTSI) del instituto electoral capitalino diseñe un espacio digital que contendrá los siguientes elementos:

- Deberá establecer los permisos para que la ciudadanía participe en las asambleas que les correspondan. Esto es así porque, por ejemplo, un habitante de la UT de Palmatitla (en la alcaldía Gustavo A. Madero) no puede participar con derecho a voz y voto en una asamblea de la UT Agrícola Oriental (de Iztapalapa).

- Debe contener un apartado de registro de la ciudadanía que va a participar, para llevar un control de quienes se encuentran presentes.

- Debe tener la opción de generar foros de discusión, por medio de los cuales se efectuará la deliberación ciudadana.

- Finalmente, debe contener una opción para emitir votos ciudadanos, para el caso de la ciudadanía que esté posibilitada para hacerlo.

Asimismo, se está pensando que el ejercicio deliberativo se desarrolle en un lapso de por lo menos una semana entera, para que la ciudadanía interesada tenga la opción de emitir sus opiniones en un tiempo considerable. En las asambleas de información y selección, en las que se designará por sorteo a los Comités de Ejecución y Vigilancia, dicho procedimiento se deberá llevar a cabo mediante transmisiones en vivo, para dar certeza sobre los nombres de la ciudadanía que resulte insaculada. Igualmente, se está considerando que se generen pruebas piloto de conectividad y que exista capacitación virtual para las personas encargadas de convocar a las asambleas y para la ciudadanía en general. ${ }^{7}$

Al igual que el de la Ciudad de México, la pandemia afectó también al mecanismo de Barcelona (España), donde ya no se pudieron realizar tampoco las asambleas (o sesiones presenciales) para plantear propuestas de los presupuestos participativos, las cuales se llevarían a cabo en marzo de 2020. Sin embargo las discusiones se realizaron a través de la plataforma participativa Decidim.Barcelona, por medio de la cual se pudo desahogar la fase de debate y de presentación de propuestas. En el presupuesto participativo de Barcelona se tienen contempladas cuatro fases: I. debate y recogida de propuestas; II. validación política y técnica de las propuestas;

7 En América Latina hay ejemplos significativos sobre ejercicios deliberativos usando la tecnología. Uno de ellos son las conferencias nacionales de políticas públicas de Brasil, donde, debido a la expansión del proceso participativo se abrió la posibilidad de que la ciudadanía participara también en línea (Pogrebinschi, 2012). 
III. retorno; y, IV. seguimiento. La primera etapa concluyó el 22 de mayo de 2020 (y se llevó a cabo de manera remota) y la siguiente se realizará del I de julio al 30 de septiembre (Plataforma Decidim.Barcelona). Éste es otro ejemplo emblemático de innovación en tiempos del coronavirus.

En suma, lo importante y destacable es que I) la pandemia afecta más a los ejercicios participativos (en comparación con los electorales) por la complejidad de su ejecución (especialmente de los de innovación democrática); y, 2) los procesos políticos en general se están reinventando, en la medida de lo posible, $y$ en este punto las TIC se manifiestan como los instrumentos más valiosos para hacerlo. Es decir, el voto electrónico ya no es la única alternativa tecnológica en medio de la emergencia sanitaria y para ejercicios de participación ciudadana más elaborados se vuelve indispensable pensar en formas más novedosas para garantizar que la ciudadanía incida en el proceso de toma de decisiones.

\section{REFLEXIÓN FINAL}

En todos los ejemplos de aplazamiento de procesos políticos por la emergencia sanitaria hay una constante: se ha privilegiado el derecho a la salud por encima del derecho político. Ambos son importantes, pero es claro que antes que la preservación de la vida humana no hay nada.

Queda claro también que hay procesos participativos que son más complejos por las propias características que los distinguen. En estos casos, se insistió que la afectación provocada por la pandemia fue significativa, pero puede mitigarse con el uso de las tecnologías.

Se deja en el tintero la reflexión acerca de que la generación de confianza en la tecnología por parte de actores políticos y sociales involucrados en estos procesos participativos, puede ser más rápida y eficiente que en los procesos electorales. Esto es así porque siempre se le ha dado más peso a la renovación de representantes populares (sobre todo si se trata de los ejecutivos nacionales) que a la toma de decisiones derivada de un mecanismo de democracia directa o de innovación democrática. En cualquiera de los casos, se debe garantizar que las alternativas derivadas del empleo de las TIC sean seguras, amigables para sus usuarios, accesibles y que no se viole la voluntad popular.

De cualquier manera, también se explicó que la distinción de la participación ciudadana de otros tipos de participación (especialmente la política) ayuda a identificar con mayor claridad sus distintas expresiones y también las afectaciones específicas por la emergencia sanitaria que se hace manifiesta a nivel global. Lo cual también permitió reconocer las alternativas que se han diseñado en casos específicos para contrarrestar sus efectos, en la medida de lo posible, y seguir fortaleciendo a las democracias. 


\section{REFERENCIAS}

Avritzer, L. (2013). "Democratic, Innovation and Social Participation in Brazil", en Taiwan Journal of Democracy, Vol. 9, Núm. 2, pp. 153-170.

Ayala Sánchez, A. y Hernández Polanco, J. R. (2014). “Los presupuestos participativos, una estrategia de diálogo entre ciudadanos y autoridades", en Alfonso Ayala Sánchez (Coord.), Nuevas avenidas de la democracia contemporánea, México: Universidad Naciona Autónoma de México, Instituto de Investigaciones Jurídicas, Serie Doctrinaria Jurídica, Núm. 7, pp. 75-90.

Colombo Vilarrasa, C. (2006). "Innovación democrática y TIC, ¿hacia una democracia participativa?". En Segundo Congreso sobre Internet, derecho y política: análisis y prospectiva [monográfico en línea]. IDP. Revista de Internet, Derecho y Política. Núm. 3. UOC.

Convocatoria Única para la elección de las Comisiones de Participación Comunitaria 2020 y la consulta de Presupuesto Participativo 2020 y 2021. IECM, 16 de noviembre de 2019.

Cunill, N. (1991). Participación ciudadana. Dilemas y perspectivas para la democratización de los Estados latinoamericanos. Caracas: Centro Latinoamericano de Administración para el Desarrollo (CLAD).

Dagnino, E., Olvera, J. A. y Panfichi, A. (2007). "Innovación democrática en América Latina: Una primera mirada al proyecto democrático-participativo". Documento de trabajo presentado en el Seminario Democratic Innovation in the South, San José, Costa Rica, 5 y 6 de marzo.

de Souza Santos, B. (2003). Democracia y participación. El ejemplo del presupuesto participativo de Porto Alegre, Trad. María del Mar Portillo, Ediciones Afrontamiento Lda. Portugal.

Francés García, F. J., García García, J. T. y Santacreu Fernández, O. A. (2007). "Modelos participativos e innovación democrática local en los municipios valencianos", Documento de trabajo presentado en el IX Congreso Español de Sociología, septiembre.

Gobierno de México (2020). “Conferencia 15 de marzo”. Comunicado Técnico Diario, Información internacional y nacional sobre nuevo coronavirus con corte al 15 de marzo de 2020. Disponible en https://coronavirus.gob. mx/2020/03/15/conferencia-15-de-marzo/

Goldfrank, B. (2006). “Los procesos de 'presupuesto participativo' en América Latina: éxito, fracaso y cambio”, en Revista de Ciencia Política, Vol. 26, Núm. 2, pp. 3-28.

Hernández Trejo, N. E. (2020). Innovación democrática y las condicionantes de la participación ciudadana: análisis del presupuesto participativo en la Ciudad de México. Tesis doctoral del Programa de Posgrado en Ciencias Políticas y Sociales de la UNAM, defendida el 12 de febrero. 
Hodge, N. e Ilyushina, M. (2020, 1 de julio). "Votantes rusos respaldan de manera abrumadora una reforma de Putin que le abre el camino para gobernar hasta 2036", en CNN, Secc. Breaking News. Consultado el 21 de agosto de 2020 en https://cnnespanol.cnn.com/2020/07/01/votantesrusos-respaldan-de-manera-abrumadora-una-reforma-de-putin-que-leabre-el-camino-para-gobernar-hasta-2036/

Instituto Electoral de la Ciudad de México, IECM. Portal oficial www.iecm.mx Ley de Participación Ciudadana de la Ciudad de México (2019). 19 de agosto de 2019.

Marquina Sánchez, L. (2013). "Capital social y desarrollo territorial en la ciudad de México: una reflexión a partir de los presupuestos participativos", en Debate DRd Revista eletronica do Programa de Mestrado em Desenvolimento Regional de Universidade do Contestado, Año 3, Núm. 2, julio-diciembre, pp. 100-113.

Martínez, J. P. (2020, 25 de marzo). "México celebra una consulta ciudadana en pleno auge de los contagios por COVID19", en El Salto, Edición General. Consultado el25 de agosto de 2020 en https://www.elsaltodiario.com/coronavirus/mexico-celebra-consulta-ciudadana-cerveceraagua-pleno-auge-contagios-covid19

Organización de Estados Americanos (OEA) (2020). Guía para organizar elecciones en tiempos de pandemia, Departamento para la Cooperación y Observación Electoral, Secretaría para el Fortalecimiento de la Democracia, $223 \mathrm{p}$.

Pasquino, G. (2011). Nuevo curso de ciencia política, México: Fondo de Cultura Económica, 2011.

Plataforma participativa Dedicim.Barcelona. (Consultada el 26 de agosto de 2020).

Pogrebinschi, T. (2012). "Participación como representación: generación democrática de políticas públicas en Brasil”, en Cameron, Maxwell A., Hershberg, Eric y Sharpe, Kenneth E. (Edits.), Nuevas instituciones de democracia participativa en América Latina: la voz y sus consecuencias, Flacso, México.

Rincón, A. (2020, 23 de marzo). "Referendo constitucional en pleno estallido del COVID-19 eleva tensiones en Guinea", en France24. Consultado el 21 de agosto de 2020 en https://www.france24.com/ es/20200322-covid19-guinea-referendo-constitucional-tensiones

Rodea, F. (2016, 4 de septiembre). "Entre denuncias, capitalinos eligen comités vecinales", en El Financiero, Secc. Nacional, consultado el 9 de febrero de 2018 a través de la siguiente dirección URL: http://www.elfinanciero.com.mx/nacional/entre-denuncias-capitalinos-eligen-comitesvecinales.html 
Velásquez, F. y E. González (2004). La planeación participativa en Bogotá D.C. análisis y propuestas. Foro Nacional Por Colombia. Bogotá: Fundación Corona.

Welp, Y. y Massüger, N. (2013). “De Suiza a América Latina: desafíos de la democracia directa", Cuadernos del ICGDE 6.

Zermeño, S. (2004). "La participación ciudadana bajo los gobiernos perredistas del Distrito Federal (1997-2003)”, en Alicia Ziccardi (Coord.), Participación ciudadana y políticas sociales del ámbito local, México: Instituto de Investigaciones Sociales de la UNAM, Instituto Nacional de Desarrollo Social y Consejo Mexicano de Ciencias Sociales, pp. 145-166. 